\title{
Analysis of the Efficiency of New Retail Industry in Provinces of China Based on DEA Method
}

\author{
Lefei $\mathrm{Li}$ \\ School of Management \\ Wuhan University of Technology \\ Wuhan, China 430070
}

\author{
Shi Tian \\ School of Materials \\ Wuhan University of Technology \\ Wuhan, China 430070
}

\begin{abstract}
At present, the new retail business has gradually been developed, and the retail industry in China is facing a transformation and upgrading, which means challenges and competition for all provinces and regions. This paper aims to establish a DEA model to evaluate the efficiency of provincial new retail industry, and the twenty-five provincial administrative districts are selected as an sample to measure and analyze the new retail efficiency of each province, finally the problems faced by the new retail business will be found out, and then the paper will propose some improvement measures and suggestions.
\end{abstract}

Keywords-DEA; new retail; Malmquist model; total factor productivity

\section{INTRODUCTION}

Since the generation of the concept of "new retail", the explosive growth of consumption is reshaping the pattern of the economic rise. The provinces have taken the main central cities in their jurisdictions as the starting point, and then they have launched serious competition under this new mode. In the business context of the consumption upgrade and the retail industry transformation, it is of great significance to analyze the efficiency and influencing factors of the new retail industry in different provinces in order to improve the regional new retail environment and promote the coordinated and efficient development of the new retail business. There is an imbalance in the development efficiency of the new retail in different provinces. This imbalance is mainly related to the difference between the total factor productivity of retail in the provinces and the investment factors of the new retail. Therefore, this paper selects the panel data in twenty-five provinces, municipalities and autonomous regions from 2012 to 2016 in China (other provinces are not analyzed due to lack of the statistical data), and then the DEA model and Malmquist productivity index are used to measure and analyze the efficiency and dynamics of retail industry in different provinces of China, and the efficiency of retail industry in different provinces is objectively evaluated as well as the total factor productivity and the growth trend of the retail industry are analyzed. Based on that, the inputoutput efficiency's index system of the new retail business of the provinces and regions was established, and the new retail efficiency of the twenty-five provinces and regions was evaluated by the DEA method in order to provide some reference for the development of the new retail industry in different regions, and finally the overall efficiency level of the new retail industry will be improved.

\section{LITERATURE REVIEW}

At present, the development of the new retail is a hot issue researched by scholars. With the comprehensive transformation and upgrading of China's retail industry, the evaluation of the new retail efficiency will provide an important evidence for the rational allocation of resources in the retail industry and the development direction of new retail industry in regions. At present, in terms of the regional retail efficiency measurement and new retail efficiency evaluation, the scholars have mainly made the following related research: You Jianxin and Chen Jiangning (2007), who established the input-output system of the retail enterprises, and they firstly analyzed the operations efficiency of the retail business through the DEA method [1]. Qiu Jun(2016) applied the DEA model with three-stage and the Malmquist index to analyze the above designated panel data of retail enterprises in thirty-one provinces and regions from 2008 to 2013, and then they analyzed the alterable relationship of the total factor productivity [2]. Peng Hui and Zhou Zhen (2016) used the dynamic factor analysis method to establish competitiveness evaluation index system in the retail business, and they comprehensively evaluated the competitiveness level of the retail industry in China from 2002 to 2014[3]. Liu Yalan (2018), with the example of the new retail leaders such as Alibaba and JD.com, she analyzed the development of China's new retail industry and proposed the guiding recommendations for the market development of China's new retail.

From the present research results, the research on the development of the regional new retail has just started, so a perfect theoretical system is lacked; in the empirical research, only the empirical analysis of the efficiency of regional traditional retail industry and the timeliness is insufficient; the research on the empirical analysis of the regional new retail efficiency is insufficient. It is precisely because of these shortcomings that it is necessary to strengthen the research in this aspect. 


\section{RESEARCH METHODS AND SOURCES OF DATA}

\section{A. Research Methods}

1) DEA (Data Envelopment Analysis) method: the DEA is an effective method to compare the relative efficiency and effectiveness of several similarity of multiple input-output decision making units (DMUs). The basic idea is to regard the evaluation unit as a decision-making unit and then compare the different decision-making units and analyze the input-output, finally the input and output indicators of relevant decision-making units are used as weights to determine the production frontier. The distance between the production frontier and the decision unit was determined to whether the decision unit is valid. The CCR model assumes that the scale returns are constant and the comparative efficiency value of each decision unit is calculated. The CCR model transforms the multi-input and multi-output model into a virtual single-input and single-output model, which simplifies the calculation process and obtains the most beneficial weights of the input and output variables and finally the maximum DMU integration efficiency is obtained. The CCR model assumes $\mathrm{n}$ decision-making units (DMU), which are comparable, each unit has $\mathrm{i}$ inputs (it represents the consumption of elements about each decision unit) and $\mathrm{j}$ outputs (The result is obtained after the decision units consume the element). Taking each province as the decision-making unit, it is assumed that there are $\mathrm{k}$ decisionmaking units, and each decision-making unit has $\mathrm{L}$ input indicators and $\mathrm{M}$ output indicators. The xjl represents the input of the first resource of the $\mathrm{j}$-th province, and the yjm represents the output of the $\mathrm{m}$-th resource of the $\mathrm{j}$-th province $(j=1,2, \cdots, K ; l=1,2, \cdots, L ; m=1,2, \cdots, M)$, then the nth province has a model based on the constant scale return under the assumption of convexity, cone, invalidity and validity axiom ( CCR model), it could be expressed as:

$$
\begin{aligned}
& \min \left[\theta-\varepsilon\left(\hat{e}^{T} s^{-}+e^{T} s^{+}\right)\right] \\
& s . t . \sum_{j=1}^{k} x_{j 1} \lambda_{j}+s^{-}=\theta x_{i s}^{n} \sum_{j=1}^{k} y_{j m} \lambda_{j}-s^{+}=y_{m}^{n} ; \\
& \lambda_{j}, s^{-} s^{+} \geq 0, n=1,2, \ldots K
\end{aligned}
$$

Where: $\theta(0<\theta \leq 1)$ is the comprehensive efficiency index of the new retail industry in each province; the $\lambda j$ is the weight variable; the $\mathrm{S}$ - is the slack variable; $\mathrm{S}+$ is the residual variable; the $\varepsilon$ is the non-Archimedes infinitesimal; the êT $=(1,1, \cdots, 1) \in \mathrm{EL}$ and $\mathrm{eT}=(1,1, \cdots, 1) \in \mathrm{EM}$ is the unit vector space. When the value of $\theta$ is larger, the efficiency of the new retail industry is higher. The $\theta=1$ indicates that the efficiency of the new retail industry in the province is on the optimal production frontier, and its output that is relative to the input has achieved the optimal overall efficiency. This paper selects the CCR model for calculation and evaluates the new retail efficiency of each province.

The BCC model is the main model used for efficiency analysis of DEA and it was proposed by Banker, Charnes and Cooper in 1984. In the actual production, many production units are not in the optimal production state, so the technical efficiency derived from the CCR model includes the contents of scale efficiency. In the constraints of the CCR model, the convexity hypothesis is added, and the equation (1) could be transformed into a variety model with scale return (BCC model). The $\mathrm{BCC}$ model could be used to decompose the overall efficiency into the product of pure technical efficiency and scale efficiency. The efficiency index (denoted as $\theta \mathrm{b}$ ) obtained by the BCC model is the pure technical efficiency index and $0<\theta b \leq 1$ and $\theta b \geq \theta$. The scale efficiency (SE) could be calculated by the equation SE $=\theta / \theta \mathrm{b}, 0<\mathrm{SE} \leq 1$. Similarly, the closer values of $\theta \mathrm{b}$ and $\mathrm{SE}$ are to 1 , the higher the pure technical efficiency and the scale efficiency. The BCC model is used in the paper while measuring the efficiency of retail industry in each province and calculating the total factor productivity of retail industry.

2) Malmquist productivity index method: when calculating the total factor productivity of the retail industry in each province, the DEA method cannot clearly reflect its changing trend in the time dimension and the main factors causing the change. The Malmquist Productivity Index method provides an effective means to analyze the changes in the total factor productivity of retail industry in various regions. It could solve the insufficient problem of the relative efficiency of the BCC model. It was first proposed by the Swedish economist and statistician-Malmquist.S in 1953.

The Malmquist productivity index change decomposes the change in total factor productivity into the technological progress and technological efficiency changes. In the case of the variable scale efficiency, the decomposition is:

$$
T F P_{\text {ch }}=E f f_{\text {ch }} \times T E_{\text {ch }}(2)
$$

In the formula, TFPch $>1$ indicates the increase of the total factor productivity from $t$ period to $t+1$ period, and vice versa; TEch (Technical Change) is the technological progress, which reflects the contribution of the movement of the production frontier to the productivity change, if TEch> 1, representing technological progress, and vice versa; Effch (Efficiency Change) represents the technical efficiency change, if Effch $>1$, it means the improvement of technical efficiency, and vice versa. TEch and Effch $>1$ indicate that it has a positive effect on the improvement of the total factor productivity (TFP), and vice versa.

\section{B. Indicator Selection and Source of Data}

The efficiency of regional retail industry reflects the input-output relationship of the industry. The input factors include labor units, labor, and capital. The input indicators used in the present research mainly include above designated the number of legal enterprises, the number of employees, and total assets of retail business. The output mainly refers to the economic benefits of the retail industry. The existing measurement indicators mainly include the main business income of the retail business above the designated size, the profit of the main business, the main business tax and surcharges.

According to the existing research results, and then to ensure that the indicators are independent and measurable, 
the data is easy to operate and obtain. When measuring the regional retail efficiency, this paper selects the above the designated legal industry of retail business, the number of employees and the total assets as the input indicators and selects the main business income of the retail business above the designated size and the profit of the main business as the output indicators.

When calculating and evaluating the new retail efficiency in each province, the digital business index, consumption upgrade index, policy index and the change rate of total factor productivity calculated in the regional retail industry efficiency measurement are selected as the input index, and the service efficiency index, consumption activity are selected as a output indicator, the new retail efficiency of each province is measured.

The research data mainly origins: 1 .The annual data of the province of the Chinese National Bureau of Statistics from 2012 to 2016; 2.The Digital Economic Think Tank "China's New Retail City-Competitiveness and Commercial Reconstruction"; 3. Guanghua School of Management, Peking University - 2018 Development Index Report of New Retail City.

\section{Provincial Sample Selection}

In the sample selection, the availability of data is the main basis, the twenty-five provinces and regions were selected as the research samples (including Central China, North China, East China, South China and Northeast China, and several northwestern provinces, Tibet, Hong Kong, Macao and Taiwan regions are difficult to obtain the data, so they are not selected as a sample), the retail efficiency measurement and the calculation of the change rate of total factor productivity are carried out; in the calculation and evaluation of the new retail efficiency of the province, the new retail competitiveness of a province largely depends on its central city, therefore, the central cities are selected to represent the 25 provinces and regions to be the sample.

\section{ANALYSIS OF THE EFFICIENCY OF NEW RETAIL INDUSTRY IN THE PROVINCES}

\section{A. The Rate of Change of Total Factor Productivity (TFP) of Regional Retail Industry}

The raw data were obtained from the retail sales data of the above-mentioned provinces and autonomous regions in China National Bureau of Statistics from 2012 to 2016. The data was processed using the MaxDEA. The DEAMalmquist model was used to obtain four sets of change rate data of the total factor productivity (TFP), they were respectively from 2012 to 2013,2013 to 2014,2014 to 2015 , and 2015 to 2016, the four sets of change rate data were geometrically averaged, and the annual average rate of change of total factor productivity in five years was shown in "Table I".
TABLE I. ANNUAL AVERAGE RATE OF CHANGE OF TFP IN VARIOUS PROVINCES AND REGIONS FROM 2012 TO 2016

\begin{tabular}{|l|l|l|l|}
\hline \multicolumn{1}{|c|}{ Region } & $\begin{array}{c}\text { Rate of } \\
\text { Change TFP } \\
(\mathbf{\%})\end{array}$ & \multicolumn{1}{|c|}{ Region } & $\begin{array}{c}\text { Rate of Change } \\
\text { TFP (\%) }\end{array}$ \\
\hline Hubei & 107.578 & Anhui & 103.471 \\
\hline Beijing & 107.026 & Hujian & 107.019 \\
\hline Tianjin & 102.536 & Jiangxi & 100.550 \\
\hline Hebei & 100.585 & Shandong & 103.343 \\
\hline Shanxi & 95.311 & Henan & 101.781 \\
\hline Liaoning & 100.894 & Hunan & 92.267 \\
\hline Jilin & 97.031 & Guangdong & 108.136 \\
\hline Heilongjiang & 100.850 & Guangxi & 102.965 \\
\hline Shanghai & 107.107 & Chonqing & 101.813 \\
\hline Jiangsu & 108.376 & Sichuan & 104.445 \\
\hline Zhejiang & 102.340 & Guizhou & 103.193 \\
\hline Xinjiang & 99.088 & Yunnan & 103.674 \\
\hline Shanxi & 102.459 & & \\
\hline
\end{tabular}

It could be seen from the data in "Table I" that the average annual rate of change of TFP in Jiangsu, Guangdong and Hubei is among the top three in the country, which reflect that the progress of the retail industry efficiency in these three provinces is more obvious; while the annual rate of change of TFP of Hunan, Shanxi, Jilin, Xinjiang in the four provinces is less than 1, indicating that total factor productivity has declined in the five years from 2012 to 2016. The rate of change in the above table will be used as an input indicator to measure and evaluate the efficiency of new retail industries in each province.

\section{B. Measurement and Evaluation of the Efficiency of New Retail Industry}

According to the data provided by the Digital Economy Think Tank, and Guanghua School of Management in Peking University, and the average annual rate of change of TFP obtained in the previous DEA analysis, and processed by MaxDEA software, under the selection of the constant scale return (CCR) model, the following result in the "Table II" was obtained. In "Table II", s-1, s-2, s-3, s-4, s+1, and $s+2$ are the values of the every slack variables in the CCR model, and $\theta$ is the effective value of the relative DEA. The magnitude of $\theta$ indicates the level of the efficiency of the new retail industry in each province. The slack variables for each input indicator in "Table II" indicate the amount of input that the input indicator could reduce, and the slack variable for each output indicator indicates the amount that could be increased. 
TABLE II. CALCULATION Results of DEA EFFiciency AND SCALE BENEFIT

\begin{tabular}{|l|l|l|l|l|l|l|l|l|}
\hline \multicolumn{1}{|c|}{ 10Province } & \multicolumn{1}{|c|}{$\boldsymbol{\theta}$} & \multicolumn{1}{|c|}{$\mathbf{s - 1}$} & \multicolumn{1}{|c|}{$\mathbf{s - 2}$} & \multicolumn{1}{|c|}{$\mathbf{s - 3}$} & \multicolumn{1}{|c|}{$\mathbf{s - 4}$} & \multicolumn{1}{|c|}{$\mathbf{s + 1}$} & \multicolumn{1}{|c|}{$\mathbf{s + 2}$} & \multicolumn{1}{c|}{ RTS } \\
\hline Hubei & 0.920 & 0 & -10.282 & -27.313 & 0 & 0 & 0 & drs \\
\hline Beijing & 0.932 & 0 & -7.970 & -51.700 & 0 & 0 & 1.942 & drs \\
\hline Tianjin & 0.934 & 0 & -4.272 & -18.433 & 0 & 0 & 2.677 & drs \\
\hline Hebei & 0.959 & 0 & -4.424 & -4.615 & 0 & 0 & 0.520 & drs \\
\hline Shanxi & 1.000 & 0 & 0 & 0 & 0 & 0 & 0 & - \\
\hline Liaoning & 0.938 & 0 & -2.073 & -8.518 & 0 & 0 & 0.462 & drs \\
\hline Jilin & 1.000 & 0 & 0 & 0 & 0 & 0 & 0 & - \\
\hline Heilongjiang & 0.951 & 0 & 0 & -9.352 & 0 & 0 & 1.253 & drs \\
\hline Shanghai & 0.984 & 0 & -13.076 & -54.998 & 0 & 0 & 4.087 & drs \\
\hline Jiangsu & 0.893 & 0 & -2.574 & -17.615 & 0 & 1.971 & 0 & drs \\
\hline Zhejiang & 0.994 & 0 & -3.959 & -6.920 & 0 & 7.851 & 0 & drs \\
\hline Anhui & 0.925 & 0 & -8.116 & 0 & -10.538 & 0.300 & 0 & drs \\
\hline Fujian & 0.883 & 0 & -2.634 & 0 & -1.275 & 2.146 & 0 & drs \\
\hline Jiangxi & 1.000 & 0 & 0 & 0 & 0 & 0 & 0 & - \\
\hline Shandong & 0.934 & 0 & 0 & -2.603 & -0.802 & 2.901 & 0 & drs \\
\hline Henan & 0.924 & 0 & -0.070 & 0 & -1.439 & 1.232 & 0 & drs \\
\hline Hunan & 1.000 & 0 & 0 & 0 & 0 & 0 & 0 & - \\
\hline Guangdong & 0.938 & 0 & 0 & -31.390 & 0 & 3.047 & 0 & drs \\
\hline Guangxi & 0.998 & -2.421 & -3.234 & 0 & 0 & 0.673 & 0 & drs \\
\hline Chongqing & 0.918 & 0 & 0 & -14.622 & 0 & 0 & 1.980 & drs \\
\hline Sichuan & 0.920 & 0 & -0.879 & -11.848 & 0 & 0.109 & 0 & drs \\
\hline Guizhou & 1.000 & 0 & 0 & 0 & 0 & 0 & 0 & - \\
\hline Yunnan & 0.973 & -1.613 & 0 & -2.913 & 0 & 0.462 & 0 & drs \\
\hline Shanxi & 0.928 & 0 & 0 & 0 & -4.291 & 2.210 & 0 & drs \\
\hline Xinjiang & 1.000 & 0 & 0 & 0 & 0 & 0 & 0 & - \\
\hline
\end{tabular}

1) Efficiency analysis: it could be seen from the relative DEA RMS values in Table 2 that the effective values of Shanxi, Jilin, Jiangxi, Hunan, Guizhou, and Xinjiang Autonomous Region are all 1 , and the slack variables are all 0 , which indicates that these six provinces an DEA effective decision making unit. The above calculations show that effective DMU is not the most developed provinces in economical basis and the retail industry, while the average effective value is 0.937 in the most developed regions such as Beijing, Shanghai, Jiangsu, and Guangdong, which is lower than the average of 0.969 in 25 provinces. It shows that the input factors have not achieved the effective output. The provinces with the lower efficiency values should increase the efficiency of new retail services and stimulate the consumer activity.

2) Scale benefit analysis: the effective value (scale efficiency score) is decomposed to obtain the scale benefit status of each DMU. The six provinces with effective value are 1, almost all provinces and regions are diminishing in scale profit. According to the economics theory, the optimal production state should be in the stage of decreasing scale on the production frontier. Therefore, the results of the scale-benefit analysis show that the development of new retail in the country has developed rapidly and reached a high level of development, but there is a problem of overheating. In the future, most provinces and regions should optimize resource allocation and rationally adjust the policy orientation. For the new retail industries, they should rationally judge and promote the stable and pretty development.

\section{CONCLUSION}

DEA analysis is an effective method for measuring the efficiency of new retail industry and conducting the comparative analysis of efficiency. This method could reflect the comprehensive efficiency, pure technical efficiency, scale efficiency, frontier projection and scale benefit status of each decision-making unit. The decision makers could evaluate and judge by efficiency, and further assist decisionmaking through the data information such as scale benefit, and finally it will greatly improve the reliability and the data support of decision-making.

Through the calculation and analysis of this paper, the retail industry in our country has improved well in recent years, and the new retail industry is developing rapidly. However, there are certain differences in efficiency between provinces and regions. The efficiency of new retail industries in most provinces and regions could be further improved space. In order to improve efficiency, the most important ways are to effectively utilize new retail driving, and it should vigorously promote the mobile payment, enhance the foundation of the digital economic development, and support the landing and infrastructure of the new retail enterprises, and rationally improve and upgrade the support policy environment of the new retail. In addition, one should reduce the problem of inefficient service caused by the blind investment, and then enhance the service experience of the new retail, promote the consumer recognition of new retail, and finally increase the consumer activity. 


\section{REFERENCES}

[1] Youjianxin, Chen Jiangning. An Analysis of the Operating Efficiency of Retail Enterprises Based on DEA Method [J]. Shanghai Management Science, 2007 (03): 17-19.

[2] Wang Xinyu. Evaluation of the Operating Efficiency of Urban Department Store Retail Enterprises Based on DEA Model [J]. Systems Engineering, 2001 (01): 56-60.

[3] Qiu Jun. An Empirical Study on Total Factor Productivity in China's Retail Industry [D]. Nanjing University of Finances and Economics, 2016.

[4] Peng Hui, Zhou Zhen. A Comparative Study of Regional Competitiveness of Retail Industry in China [J]. Journal of Beijing Technology and Business University (Social Science Edition), 2016, 31 (04): 40-50.

[5] Liu Yalan. Analysis of the Development of New Retail Business in China [J]. Business Economy, 2018 (09): 80-83.

[6] Wang Hefeng, Shi Yishao, Yin Changying. Land Use Efficiency and Change of Shanghai Development Zone Based on DEA Model and Malmquist Productivity Index [J]. Geographic Study, 2014, 33 (09): 1636-1646

[7] Chen Xueting, Song Tao, Cai Jianming, Li Le and Deng Yu. Analysis of Metabolic Efficiency of Chinese Cities Based on DEA and Malmquist [J]. Geographic Science, 2015, 35 (04): 419-426. 